\title{
Correction to: Tracking cognitive impairment in multiple sclerosis using the Brain on Track test: a validation study
}

\author{
Luis Ruano ${ }^{1,2,3}$ - Mariana Branco ${ }^{1,2} \cdot$ Milton Severo $^{2,3}$ • Andreia Sousa ${ }^{1}$ - Juliana Castelo ${ }^{1} \cdot$ Isabel Araújo ${ }^{1}$. \\ Joana Pais $^{3}$ • João Cerqueira ${ }^{4,5,6}$ - Maria Pia Amato ${ }^{7,8} \cdot$ Nuno Lunet $^{2,3}$ • Vítor Tedim Cruz ${ }^{1,3,9}$
}

Published online: 12 November 2019

(C) Fondazione Società Italiana di Neurologia 2019

\section{Correction to: Neurological Sciences (2019) https://doi.org/10.1007/s10072-019-04088-8}

The above article was published online with an error in author name's affiliations. Affiliation 8 has to be added to Maria Pia Amato and has to be deleted from Vitor Tedim.

Publisher's note Springer Nature remains neutral with regard to jurisdictional claims in published maps and institutional affiliations.

The online version of the original article can be found at https://doi.org/ 10.1007/s10072-019-04088-8

Luis Ruano

lmruano@gmail.com

1 Neurology Department, Centro Hospitalar de Entre Douro e Vouga, Santa Maria da Feira, Portugal

2 Departamento de Ciências da Saúde Pública e Forenses e Educação Médica Faculdade de Medicina da Universidade do Porto, Porto, Portugal

3 EPIUnit, Institute of Public Health, University of Porto, Rua das Taipas 135-139, 4050-600 Porto, Portugal

4 2CA Braga, Braga, Portugal
5 Life andHealth Sciences Research Institute (ICVS), School of Health Sciences, University of Minho, Braga, Portugal

6 ICVS/3B's - PT Government Associate Laboratory, Guimarães, Braga, Portugal

7 Department NEUROFARBA, Section Neurosciences, University of Florence, Florence, Italy

8 IRCCS Fondazione Don Carlo Gnocchi, Florence, Italy

9 Neurology Department, Hospital Pedro Hispano, Unidade Local de, Saúde de Matosinhos, Sra. da Hora, Portugal 